\title{
Contribution of range restricted and widespread species to biodiversity patterns in the Western Balkans in Southern Europe
}

\author{
Petra Bregovićf,§, Cene Fišer ${ }^{\ddagger}$, Maja Zagmajster ${ }^{\ddagger}$ \\ ‡ SubBioLab, Department of Biology, Biotechnical Faculty, University of Ljubljana, Ljubljana, Slovenia \\ $\S$ Croatian Biospeleological Society, Zagreb, Croatia
}

Corresponding author: Maja Zagmajster (maja.zagmajster@bf.uni-li.si)

Received: 12 Oct 2018 | Published: 19 Oct 2018

Citation: Bregović P, Fišer C, Zagmajster M (2018) Contribution of range restricted and widespread species to biodiversity patterns in the Western Balkans in Southern Europe. ARPHA Conference Abstracts 1: e30500. https://doi.org/10.3897/aca.1.e30500

\section{Abstract}

Species richness patterns (SRP) emerge due to overlap in species distributions. They critically depend on two parameters of species ranges: geographic position and size. An important question is which species contribute more to the observed SRP, range restricted or widespread species. Most studies concluded that the widespread species tend to influence SRP more. However, the relative importance of either may strongly depend on the study system. Here we investigated how subterranean species of different range sizes contribute to SRP in the Western Balkans. We studied spatially defined datasets of terrestrial and aquatic troglobionts, represented by beetles (Cholevidae, Carabidae, 425 species) and amphipod crustaceans (Niphargidae, 150 species), respectively. The two groups differ in dispersal capacities, and indeed distribution of their range sizes differed. The proportion of single site species reached $30 \%$ in beetles, and $21 \%$ in niphargids. Maximum linear extent (MLE) of the range exceeded $200 \mathrm{~km}$ in only $1 \%$ of beetles, but in nearly $20 \%$ of niphargids. SRP of both taxonomic groups only partly overlapped. To assess the contribution of species with different ranges on SRP, we created different subsets and compared their SRPs with full dataset SRP. Subsets were first formed by adding species one-by-one, in ascending and descending order according to range size. We used correlation analysis, with significance assessed using null models generated from randomly 
generated subsets. In the second analysis, we assigned species info four classes according to range size, and modelled which size class best explains SRP. The results showed certain differences among the two taxonomic groups, which make generalizations difficult. We find it important to evaluate the contribution of species with different ranges to overall SRP, but also to identification of local hotspots.

\section{Presenting author}

Maja Zagmajster

\section{Presented at}

$24^{\text {th }}$ International Conference on Subterranean Biology 2018, Aveiro, Portugal 